\title{
Neuroserpin Protects Neurons from Ischemia-Induced Plasmin-Mediated Cell Death Independently of Tissue-Type Plasminogen Activator Inhibition
}

\author{
Jialing Wu, ${ }^{* \dagger}$ Ramiro Echeverry, ${ }^{*}$ \\ Johanna Guzman, * and Manuel Yepes* \\ From the Department of Neurology and Center for \\ Neurodegenerative Disease, * Emory University School of \\ Medicine, Atlanta, Georgia; and the Graduate School of Tianjin \\ Medical University, ${ }^{\dagger}$ Tianjin, China
}

The serine proteinase tissue-type plasminogen activator (tPA) and the serine proteinase inhibitor neuroserpin are both expressed in areas of the brain with the highest vulnerability to hypoxia/ischemia. In vitro studies show that neuroserpin inhibits tPA and, to a lesser extent, urokinase-type plasminogen activator and plasmin. Experimental middle cerebral artery occlusion (MCAO) increases tPA activity and neuroserpin expression in ischemic tissue, and genetic deficiency of tPA or either treatment with or overexpression of neuroserpin decreases the volume of the ischemic lesion following MCAO. These findings have led to the hypothesis that neuroserpin's neuroprotection is mediated by inhibition of tPA's alleged neurotoxic effect. Ischemic preconditioning is a natural adaptive process whereby exposure to a sublethal insult induces tolerance against a subsequent lethal ischemic injury. Here we demonstrate that exposure to sublethal hypoxia/ischemia increases the neuroserpin expression in the hippocampal CA1 layer and cerebral cortex, and that neuroserpin induces ischemic tolerance and decreases the volume of the ischemic lesion following MCAO in wild-type and tPAdeficient $\left(\mathrm{tPA}^{-/-}\right)$neurons and mice. Plasmin induces neuronal death, and this effect is abrogated by either neuroserpin or the NMDA receptor antagonist MK801. Neuroserpin also attenuated kainic acid-induced neuronal death. Our data indicate that the neuroprotective effect of neuroserpin is due to inhibition of plasmin-mediated excitotoxin-induced cell death and is independent of neuroserpin's ability to inhibit tPA activity. (Am J Pathol 2010, 177:2576-2584; DOI: 10.2353/ajpath.2010.100466)
Tissue-type plasminogen activator (tPA) is a serine proteinase found in the intravascular space and the central nervous system (CNS). In the intravascular space, tPA's substrate is plasminogen ${ }^{1}$ and its main function is as a thrombolytic enzyme. In the brain tPA is expressed in the interface between endothelial cells and astrocytes, where it regulates the permeability of the neurovascular unit. ${ }^{2}$ TPA is also found in neurons, where it has been linked not only to events associated with synaptic plasticity ${ }^{3-6}$ but also with cell death. ${ }^{7,8}$

Neuroserpin (serpin PI12) is an axonally secreted member of the serpin gene family ${ }^{9}$ primarily found in neurons. ${ }^{10}$ Several studies indicate that neuroserpin inhibits tPA, and to a lesser extent urokinase-type plasminogen activator and plasmin. ${ }^{10}$ Additionally, neuroserpin message and protein are expressed in sites where either tPA message or tPA protein are also detected. Based on these observations, it has been proposed that neuroserpin is the selective inhibitor of tPA in the CNS.

Ischemic stroke is the second cause of mortality and a leading cause of disability in the world. ${ }^{11}$ The onset of cerebral ischemia is associated with neuronal depolarization, which is known to induce the release of neuronal tPA and neuroserpin. ${ }^{12}$ Accordingly, studies with animal models of cerebral ischemia have identified an increase in tPA activity ${ }^{8,13}$ and neuroserpin expression ${ }^{8}$ in the ischemic area following experimental middle cerebral artery occlusion (MCAO). Furthermore, either genetic deficiency of $\mathrm{tPA},{ }^{13}$ treatment with neuroserpin, ${ }^{8}$ or overexpression of the neuroserpin gene, ${ }^{14}$ is associated with decrease in the volume of the ischemic lesion following MCAO. These observations led to the hypothesis that neuroserpin is neuroprotective in the ischemic brain via its ability to inhibit the deleterious effects of tPA.

Supported in part by National Institutes of Health grants NS-062073 and HL-095063 (M.Y.)

Accepted for publication July 15, 2010

None of the authors disclosed any relevant financial relationships.

Address reprint requests to Manuel Yepes, M.D., Department of Neurology and Center for Neurodegenerative Disease, Whitehead Biomedical Research Building, 615 Michael St, Suite 505J, Atlanta, GA 30322. E-mail: myepes@emory.edu. 
Ischemic preconditioning is a highly preserved natural adaptive process whereby exposure to a sublethal insult induces tolerance against a subsequent lethal hypoxic/ ischemic injury. There are two types of ischemic preconditioning: early and delayed. ${ }^{15}$ In early/immediate preconditioning, treatment with the protective agent simultaneously or very close to the exposure to the lethal insult promotes cell survival. In contrast, in delayed preconditioning the development of tolerance is induced by treatment with the protective agent 24 to 72 hours before exposure to the lethal injury. Understanding the mechanisms of early/immediate ischemic preconditioning in the brain may lead to the development of an effective strategy for the treatment of patients with acute ischemic stroke. Unfortunately, in contrast with delayed preconditioning, the mechanisms leading to early/immediate preconditioning in the brain are less well understood.

Our recent studies indicate that sublethal hypoxia/ ischemia induces the release of tPA from hippocampal and cortical neurons. However, although tPA induces delayed ischemic tolerance in hippocampal neurons, it is toxic to cortical neurons. ${ }^{16}$ Here we show that sublethal ischemia increases the expression of neuroserpin in the hippocampal CA1 field and cerebral cortex. However, in contrast with IPA, neuroserpin induces a robust early/ immediate ischemic tolerance, and this effect is present not only in hippocampal but also in cortical neurons. Importantly, this neuroprotective effect is independent of inhibition of tPA activity, and instead is associated with neuroserpin's inhibition of plasmin-mediated, excitotoxininduced, cell death.

\section{Materials and Methods}

\section{Animals and Reagents}

Murine strains were male wild-type (Wt) C57BL/6J, tPA deficient $\left(\mathrm{tPA}^{-1-}\right)$ and neuroserpin deficient mice $\left(\mathrm{Ns}^{-1-}\right.$, kindly provided by Dr. Peter Sonderegger from the Department of Biochemistry, University of Zurich, Zurich, Switzerland, via Dr. Daniel A. Lawrence from the Department of Internal Medicine, Division of Cardiovascular Medicine, University of Michigan Medical School, Ann Arbor, MI), 8 to 12 weeks old, backcrossed at least seven generations into C57BL/6J mice. Experiments were approved by the Institutional Animal Care and Use Committee of Emory University, Atlanta, Georgia. Recombinant neuroserpin was a kind gift from Dr. Daniel A. Lawrence. Other reagents were human Glu plasminogen and Lys plasmin (Molecular Innovations, Novi, MI), the NMDA receptor (NMDAR) antagonist MK-801 and kainic acid (KA) purchased from Tocris Bioscience (Ellisville, MO), the nuclear marker 4'6-Diamidino-2-phenylindole dihydrochloride (DAPI; AnaSpec, San Jose, CA), and antibodies against neuroserpin (abcam ab33077, Abcam, Cambridge, MA), and the neuron-specific protein NeuN (Millipore, Temecula, CA).

\section{Neuronal Cultures and Determination of Cell Survival}

Hippocampal and cortical neurons were cultured from E19 Wt and PPA $^{-1-}$ mice as described elsewhere. ${ }^{17}$ Briefly, either the cortex or the hippocampal tissue was dissected, transferred into Hanks' balanced salt solution containing 100 units $/ \mathrm{ml}$ penicillin, $100 \mu \mathrm{g} / \mathrm{ml}$ streptomy$\mathrm{cin}$, and $10 \mathrm{~mm}$ HEPES, and incubated in trypsin containing $0.02 \%$ DNase at $37^{\circ} \mathrm{C}$ for 15 minutes. Tissue was then triturated, and the supernatant was resuspended in B27-supplemented neurobasal medium containing 2 $\mathrm{mmol} / \mathrm{L}$ I-glutamine and plated onto $0.1 \mathrm{mg} / \mathrm{ml}$ polyl-lysine-coated wells. To study the effect of hypoxia on neuronal death, hippocampal and cortical neuronal cultures were incubated with progressive concentrations of neuroserpin ( 0 to $1 \mu \mathrm{mol} / \mathrm{L}$ ) and exposed to oxygen-glucose deprivation (OGD) conditions ( $<0.1 \%$ oxygen) for 55 minutes in an anaberobic chamber (Don Whitley Scientific, Frederick, MD) followed 24 hours later by determination of cell death with the 3-(4,5-Dimethylthiazol-2-yl)-2,5-diphenyltetrazolium bromide assay (ATCC, Manassas, VA), following the manufacturer's instructions. It has been previously demonstrated that 55 minutes of OGD induces cell death in approximately $50 \%$ of the neurons. ${ }^{16} \mathrm{~A}$ subset of cells was incubated with KA $250 \mu \mathrm{mol} / \mathrm{L}$ either alone or in combination with neuroserpin $800 \mathrm{nmol} / \mathrm{L}$. To study the effect of plasmin on neuronal death, Wt neurons were left untreated or incubated with plasmin $100 \mathrm{nmol} / \mathrm{L}$ alone or in combination with either neuroserpin $800 \mathrm{nmol} / \mathrm{L}$ or MK-801 $10 \mu \mathrm{mol} / \mathrm{L}$. A subgroup of cells was incubated with plasminogen $200 \mathrm{nmol} / \mathrm{L}$ alone. Results are expressed as a percentage of cell survival observed in control cells maintained under normoxic conditions. Each experiment was performed in neurons cultured from three different animals, and each observation was repeated 20 times.

\section{Induction of Hippocampal Ischemia}

Mice were anesthetized with $4 \%$ chloral hydrate (400 $\mathrm{mg} / \mathrm{kg}$ ) administered intraperitoneally, followed by a midline skin incision and bilateral common carotid artery occlusion (BCCAO) for either 20 minutes (lethal injury) or three episodes of 1 minute of duration each and 5 minutes intervals of reperfusion in between (sublethal injury). It has been demonstrated that 20 minutes of BCCAO induce widespread neuronal death mostly in the hippocampal CA1 layer. In contrast, three episodes of BCCAO of 1 minute of duration and 5 minutes interval in between not only does not cause cell death but instead induces tolerance against a subsequent lethal insult. ${ }^{16}$

\section{Middle Cerebral Artery Occlusion and Determination of the Volume of the Ischemic Lesion}

Wt and $\mathrm{PPA}^{-1-}$ mice were anesthetized with $4 \%$ chloral hydrate $(400 \mathrm{mg} / \mathrm{kg})$ administered intraperitoneally followed by a midline skin incision. The middle cerebral artery was exposed and occluded with a $6-0$ silk suture advanced from the external carotid artery into the middle cerebral artery as described elsewhere. ${ }^{18}$ To induce le- 
thal ischemia, the occlusion was maintained for 30 minutes followed by reperfusion. To produce sublethal injury, the middle cerebral artery was occluded three times for 5 minutes with 10-minute intervals of reperfusion in between. It has been demonstrated that this protocol of middle cerebral artery occlusion does not induce cell death but instead can efficiently induce ischemic tolerance. ${ }^{19}$ Cerebral perfusion in the distribution of the middle cerebral artery was monitored throughout the surgical procedure with a laser Doppler (Perimed Inc., North Royalton, $\mathrm{OH}$ ), and only animals with a $>70 \%$ decrease in cerebral perfusion after occlusion and complete recovery after suture removal were included in this study. Heart rate, systolic, diastolic, and mean arterial blood pressure were controlled with an IITC 229 System (IITC-Lice Science, Woodland Hills, CA). Immediately after, MCAO animals were treated with either PBS or $3 \mu \mathrm{l}$ of a $20-\mu \mathrm{mol} / \mathrm{L}$ neuroserpin solution injected directly into the ischemic cortex through a 1-mm burr hole opened at bregma $(-0.22$ $\mathrm{mm})$, lateral $(3 \mathrm{~mm})$, and medial $(3 \mathrm{~mm}){ }^{20}$ To measure the volume of the ischemic lesion, 24 hours later MCAO animals were deeply anesthetized and transcardially perfused with saline solution. The brains were harvested, cut onto 2- $\mu \mathrm{m}$ sections, and stained with triphenyltetrazolium chloride (Sigma-Aldrich, St. Louis, MO). Triphenyltetrazolium chloride-stained sections were photographed, and the volume of the ischemic lesion was measured with the $\mathrm{NIH}$ Image Analyzer System as described elsewhere. ${ }^{21}$ Each experimental group included 12 mice $(n=12)$.

\section{Immunofluorescence Analysis of Neuroserpin Expression}

Six hours after lethal or sublethal BCCAO or MCAO, animals were deeply anesthetized and transcardially perfused with $4 \%$ paraformaldehyde and $10 \%$ sucrose. The brains were maintained in a $30 \%$ sucrose solution overnight and $20-\mu \mathrm{m}$ sections through the dorsal and ventral hippocampus (in those animals with BCCAO), or through the ischemic area (in those animals undergoing MCAO) were obtained with a vibratome. Each coronal section was divided into 16 square areas (150 $\mathrm{mm}^{2}$ each one) that involved the necrotic core and area of "penumbra." Three areas of interest (AOI) were chosen in the boundaries between the ischemic penumbra and necrotic core (AOI-1, -2 and -3 ), whereas a fourth zone was located in the necrotic core (AOI-4). Each section was stained with antibodies against neuroserpin (1:200 dilution) and NeuN (1:500 dilution), and co-stained with the nuclear marker DAPI. Each observation was repeated five times. To test for the specificity of the antibody against neuroserpin, we performed similar observations in $\mathrm{Ns}^{-1-}$ mice. No staining for neuroserpin was observed in the hippocampus of these animals (data not shown).

\section{Statistical Analysis}

Values are expressed as percentage or mean \pm SD when appropriate. Statistical tests included the $t$-test followed by the Wilcoxon signed-ranked test. $P$ values of less than 0.05 were considered significant.

\section{Results}

\section{Sublethal Ischemia Increases the Expression of Neuroserpin in the Hippocampus}

Previous reports have described the expression of neuroserpin in the CA1 and CA3 layers of the mouse, ${ }^{10}$ rat, ${ }^{22}$ and human ${ }^{23}$ hippocampus. Because these are among the areas of the CNS with the highest vulnerability to hypoxic/ischemic injury, we decided to study the effect of ischemia on neuroserpin expression in this hippocampal area. Wt mice were either maintained under nonischemic conditions (Figure 1, A-D) or underwent 20 minutes of BCCAO (lethal ischemia) followed 6 hours later by immunohistochemical staining for neuroserpin. We found that lethal ischemia failed to induce a significant change in the expression of neuroserpin in the CA1 and CA3 hippocampal layers (Figure 1, E-H). Because it has been demonstrated that exposure to sublethal ischemia protects hippocampal pyramidal neurons against a subsequent lethal ischemic insult, ${ }^{15}$ we studied the expression of neuroserpin 6 hours after sublethal BCCAO, performed as described in Materials and Methods. Surprisingly, we found that in contrast to lethal ischemia, a sublethal ischemic injury induces a significant increase in the expression of neuroserpin in the hippocampal CA1 and CA3 layers (Figure 1, I-L).

\section{Effect of Neuroserpin on Hippocampal Ischemic Preconditioning}

Our observations suggest that neuroserpin plays a role in the development of ischemic tolerance in the hippocampus. To test this hypothesis, we used a model of delayed ischemic preconditioning, in which Wt hippocampal neurons where incubated with progressive concentrations of neuroserpin 0 to $1 \mu \mathrm{mol} / \mathrm{L}$ for 1 hour, followed 24 hours later by exposure to OGD conditions for 55 minutes and determination of neuronal survival with the 3-(4,5-Dimethylthiazol-2-yl)-2,5-diphenyltetrazolium bromide assay. We found that exposure to OGD conditions decreased neuronal survival to $51.8+/-6.5 \%$ (black bar in Figure $2 \mathrm{~A})$ and that delayed preconditioning with neuroserpin caused a dose-dependent increase in neuronal survival to $66.3+/-1.6 \%$. In recent studies we found that TPA also induces delayed ischemic preconditioning in hippocampal neurons, ${ }^{16}$ which argues against the hypothesis that inhibition of tPA activity is the mechanism of neuroserpin's neuroprotective effect. Thus, we decided to compare the effect of neuroserpin and IPA in the induction of delayed ischemic tolerance in hippocampal neurons. Wt hippocampal neurons were incubated with neuroserpin $800 \mathrm{nmol} / \mathrm{L}$ or IPA $60 \mathrm{nmol} / \mathrm{L}$ (in previous studies we found that this concentration of tPA has a maximal effect on the induction of delayed ischemic tolerance ${ }^{16}$ ) followed 24 hours later by exposure to lethal OGD and determination of neuronal survival. Our results indicate that although treatment with neuroserpin induces delayed ischemic tolerance, this effect is significantly 


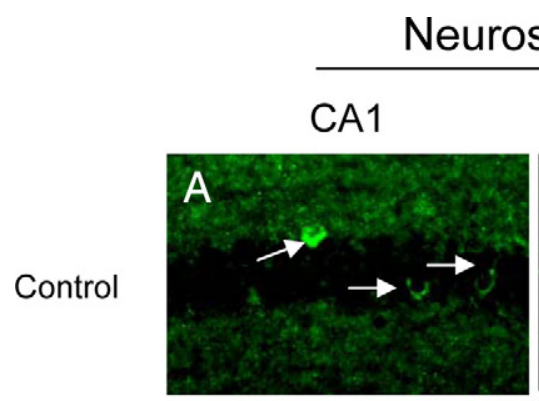

Neuroserpin

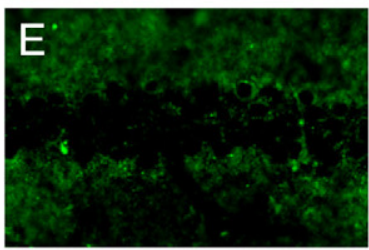

Lethal ischemia

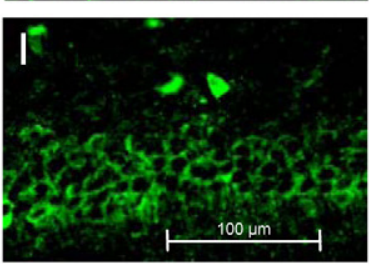

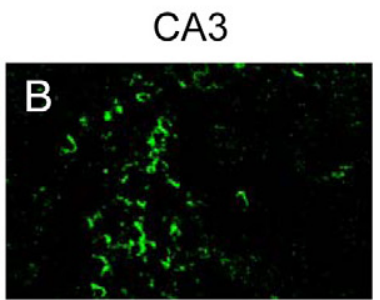
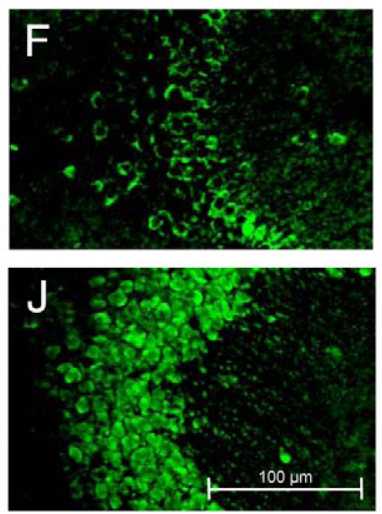

Merged
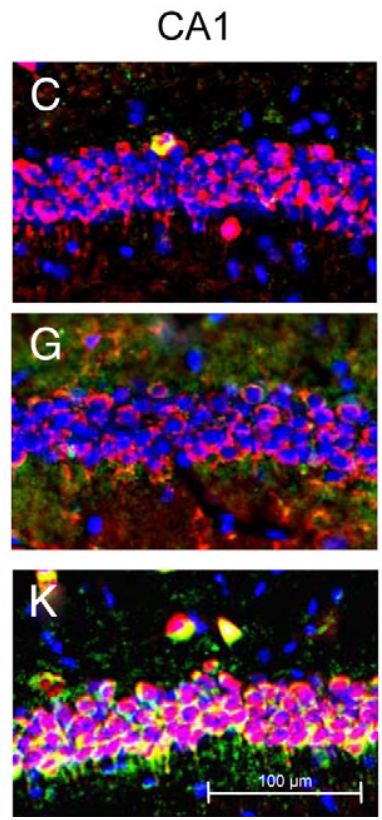
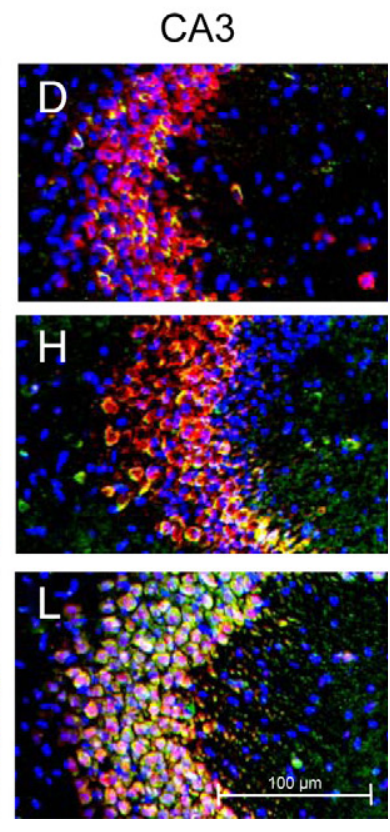

Figure 1. Sublethal ischemia induces neuroserpin expression in the hippocampal CA1 and CA3 layers. Representative micrographs from the CA1 and CA3 hippocampal layers in wild-type mice maintained under nonischemic conditions (controls, A-D) or 6 hours after either 20 minutes of BCCAO (lethal ischemia; $\mathbf{E}-\mathbf{H}$ ), or three episodes of BCCAO of 1 minute duration each with 5-minute intervals of reperfusion in between (sublethal ischemia, I-L) are shown. Green is neuroserpin, blue is DAPI, and red is the neuronal marker NeuN. Original magnification, $\times 20$. Arrows indicate the presence of scattered neuroserpin-positive cells in the CA1 layer under normoxic conditions. Each observation was repeated five times.

stronger following treatment with tPA $(66.3+/-1.6 \%$ and $78+/-3.6 \%$ neuronal survival, respectively; Figure 2B).

Then we performed similar observations in a model of early/immediate preconditioning, where Wt neurons were treated with neuroserpin 0 to $1 \mu \mathrm{mol} / \mathrm{L}$ immediately before exposure to OGD conditions for 55 minutes and determination of neuronal survival with the 3-(4,5-Dimethylthiazol-2-yl)-2,5-diphenyltetrazolium bromide assay. Our data indicate that exposure to OGD conditions decreases hippocampal neuronal survival to $58.8+/-$ $2.3 \%$ and that treatment with neuroserpin causes a dosedependent increase in neuronal survival to $66.5+/-$ $1.6 \%(600 \mathrm{nmol} / \mathrm{L})$ and $92+/-1.6 \%$ (800 nmol/L), respectively (Figure 2C). Then we compared the effect of tPA and neuroserpin in the induction of early/immediate tolerance. Our results indicate that although treatment with tPA $60 \mathrm{nmol} / \mathrm{L}$ does not induce early/immediate hypoxic tolerance, incubation with neuroserpin $800 \mathrm{nmol} / \mathrm{L}$ causes a robust increase in neuronal survival to $90+/-$ $2.6 \%$ (Figure 2D).

\section{Neuroserpin Induces Ischemic Tolerance in the Hippocampus Via a tPA-Independent Mechanism}

Together, our data suggest that IPA and neuroserpin may have divergent roles in the ischemic hippocampus. To study this possibility, we quantified neuronal survival in Wt and tPA ${ }^{-1-}$ hippocampal neurons incubated with neuroserpin $800 \mathrm{nmol} / \mathrm{L}$ and exposed to lethal OGD conditions 24 hours later. We found that OGD decreases cell survival in both Wt and $\mathrm{tPA}^{-1-}$ hippocampal neurons to $50.1+/-1.6 \%$ and $51.1+/-1.1 \%$, respectively. Surprisingly, incubation with neuroserpin increased cell survival in both $\mathrm{Wt}$ and $\mathrm{tPA}^{-1-}$ neurons to $66.6+/-1.1 \%$ and $63.6+/-1.1 \%$, respectively (Figure $3 \mathrm{~A}$ ). Then we performed similar experiments in a model of early/immediate preconditioning. Wt and $\mathrm{PPA}^{-1-}$ hippocampal neurons were incubated with neuroserpin $800 \mathrm{nmol} / \mathrm{L}$ followed immediately after by exposure to lethal OGD conditions and determination of cell survival. Our results indicate that OGD decreases neuronal survival in Wt and tPA $^{-1-}$ mice to $58.3+/-4.1 \%$ and $61+/-4.5 \%$, respectively, and that incubation with neuroserpin increases neuronal survival to $83.3+1-3.8 \%$ in Wt and $92+/-$ $1.66 \%$ in $\mathrm{tPA}^{-1-}$ cells (Figure $3 \mathrm{~B}$ ).

\section{Effect of Lethal and Sublethal Ischemia on the Expression of Neuroserpin in Cortical Neurons}

Then we decided to investigate the effect of sublethal ischemia on the expression of neuroserpin in cortical neurons. Initially we performed an immunohistochemical staining for neuroserpin in brain cuts from control nonischemic Wt mice. We found that as previously described, ${ }^{10,22,23}$ neuroserpin is expressed mainly in clusters of neurons in the cortical layers V and VI (Figure 4, $A-C)$. Then we performed similar observations in brain sections of Wt mice 6 hours after either 30 minutes of MCAO (lethal ischemia) or three episodes of intermittent MCAO (sublethal ischemia), performed as described in Materials and Methods. Our data indicate that although 
A

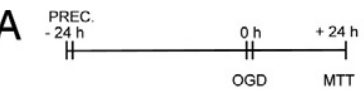

B
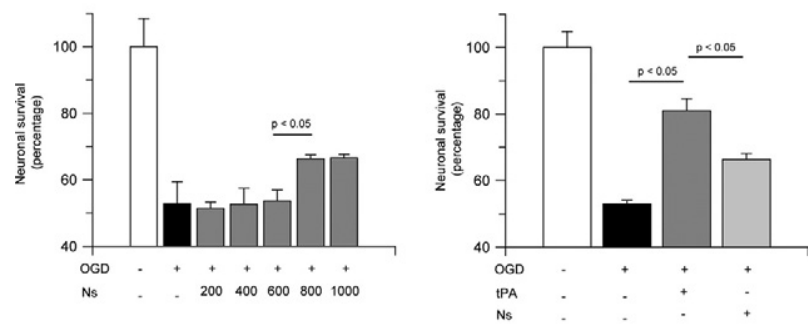

$\mathrm{C}$
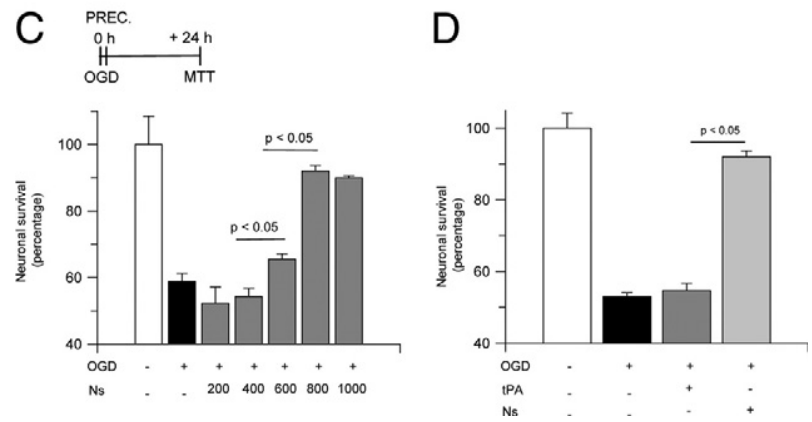

Figure 2. Neuroserpin-induced preconditioning in hippocampal neurons. A and B: Mean neuronal survival in hippocampal neurons cultured from wildtype mice and incubated either with neuroserpin 0 to $1 \mu \mathrm{mol} / \mathrm{L}(\mathbf{A})$ or tPA 60 $\mathrm{nmol} / \mathrm{L}$ (B) 24 hours before exposure to lethal hypoxia (55 minutes of OGD); $n=20$ for each observation. C and D: Mean neuronal survival in hippocampal neurons cultured from wild-type mice and incubated either with neuroserpin 0 to $1 \mu \mathrm{mol} / \mathrm{L}(\mathbf{C})$ or tPA $60 \mathrm{nmol} / \mathrm{L}$ (D) immediately before exposure to lethal hypoxia ( 55 minutes of OGD). Lines denote SD; $n=20$ for each observation. Concentrations are given in nanomolar. Ns, Neuroserpin; PREC, preconditioning, denotes the moment when cells were treated with Ns or tPA.

lethal MCAO increases neuroserpin expression in the cortical layers IV to VI (Figure 4, D-F), sublethal ischemia augments the expression of neuroserpin in all cortical layers (I to VI; Figure 4, G-I).

\section{Neuroserpin Induces Ischemic Tolerance in Cortical Neurons}

Then we decided to test the hypothesis that, as observed in the hippocampus, the increase in neuroserpin expres-
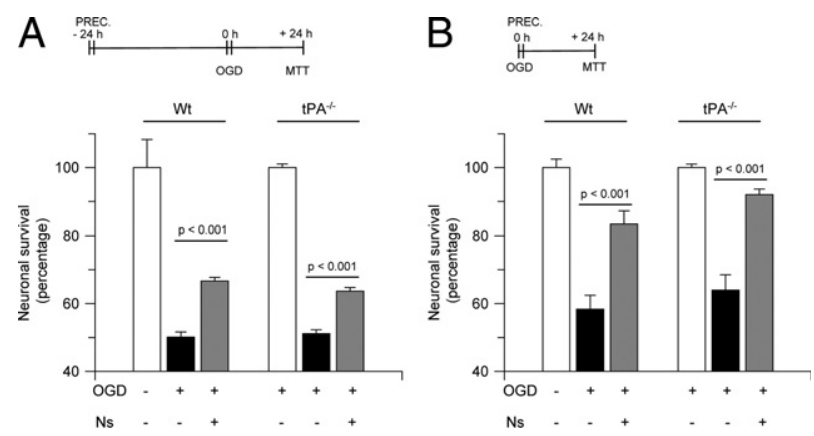

Figure 3. Inhibition of tissue-type plasminogen activator does not mediate neuroserpin-induced hypoxic tolerance in hippocampal neurons. Mean neuronal survival in hippocampal neurons cultured from Wt or tPA-deficient $\left(\mathrm{tPA}^{-/-}\right)$mice and treated with neuroserpin $800 \mathrm{nmol} / \mathrm{L}$ either 24 hours prior to (A) or immediately before (B) exposure to lethal hypoxia (55 minutes of OGD conditions). Lines denote SD; $n=15$ for each observation. Ns, neuroserpin; PREC, preconditioning. It denotes the moment when cells were treated with Ns. sion induced by sublethal ischemia in the cerebral cortex is part of a neuroprotective response against a subsequent lethal ischemic insult. To test this hypothesis, we used the model of delayed preconditioning described above. Wt cortical neurons were incubated with neuroserpin 0 to $1 \mu \mathrm{mol} / \mathrm{L}$ for 1 hour followed 24 hours later by exposure to a lethal hypoxic insult and determination of neuronal survival. We found that incubation with neuroserpin induced a dose-dependent increase in neuronal survival from $51.4+/-1.9 \%$ in untreated cells to 66.2 $+/-1.1 \%$ in neurons incubated with neuroserpin 800 $\mathrm{nmol} / \mathrm{L}$ (Figure 5A). Then we performed similar experiments in a model of early/immediate preconditioning. Wt cortical neurons were incubated with neuroserpin immediately before exposure to lethal OGD conditions and determination of neuronal survival. Our results indicate that neuroserpin induces a robust early/immediate hypoxic tolerance in cortical neurons, increasing cell survival from $53.5+/-3.50 \%$ in untreated cells to $79.80+/-$ $2.23 \%$ in neuroserpin-treated cells (Figure 5B).

Our earlier studies show that tPA induces a dosedependent decrease in cortical neuronal survival. ${ }^{16}$ Thus, we decided to investigate whether neuroserpin's early/immediate protective effect on cortical neurons was mediated by inhibition of tPA-induced cell death. TPA ${ }^{-1-}$ cortical neurons were incubated with neuroserpin immediately before exposure to lethal OGD conditions and determination of neuronal survival. Surprisingly, we found that, as observed in Wt cortical neurons, treatment with neuroserpin increased cell survival in $\mathrm{tPA}^{-1-}$ cortical neurons exposed to OGD conditions, from $44.9+/-$ $3.4 \%$ in untreated cells to $82.3+/-2.4 \%$ in cells incubated with neuroserpin $800 \mathrm{nmol} / \mathrm{L}$ (Figure 5C).

\section{Neuroserpin Protects Cortical Neurons from Excitotoxin-Induced Cell Death}

Because neuroserpin is also a plasmin inhibitor ${ }^{24}$ and plasmin has been described to interact with the NMDAR, ${ }^{16,25,26}$ and to mediate excitotoxin-induced cell death, ${ }^{27}$ we decided to test the hypothesis that the protective effect of neuroserpin was due to inhibition of plasmin-mediated, excitotoxin-induced, cell death. First, we quantified cell survival in Wt cortical neurons incubated with plasmin $100 \mathrm{nmol} / \mathrm{L}$ alone or in combination with either neuroserpin $800 \mathrm{nmol} / \mathrm{L}$ or the NMDAR antagonist MK-801 $10 \mu \mathrm{mol} / \mathrm{L}$. A subgroup of neurons was incubated with plasminogen $100 \mathrm{nmol} / \mathrm{L}$ alone. Our results indicate that compared with untreated cells, plasmin decreases neuronal survival to $74.2+/-1.7 \%$, and that this effect is significantly inhibited by co-incubation with either MK-801 (88.8 +/- 1.1\%) or neuroserpin (94 +/$1.3 \%$; Figure 6A). Based on these observations, we argued that the neuroprotective effect of neuroserpin was mediated by its ability to inhibit plasmin-mediated excitotoxic neuronal death. To further test this hypothesis, we quantified cell survival in Wt cortical neurons incubated with KA $250 \mu \mathrm{mol} / \mathrm{L}$ either alone or in combination with neuroserpin $800 \mathrm{nmol} / \mathrm{L}$. Our results indicate that incubation with KA alone reduces neuronal sur- 
Neuroserpin
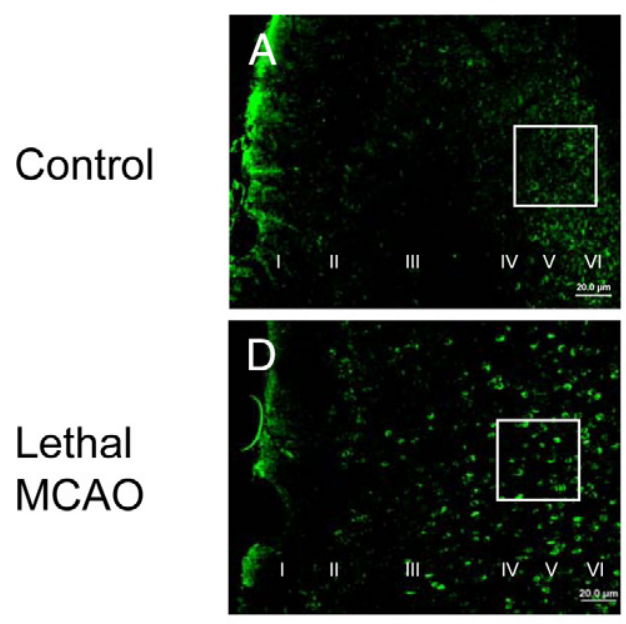

\section{Sub-lethal
MCAO}

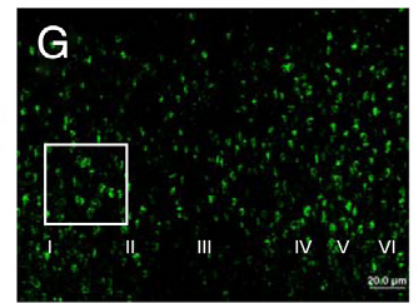

Merged
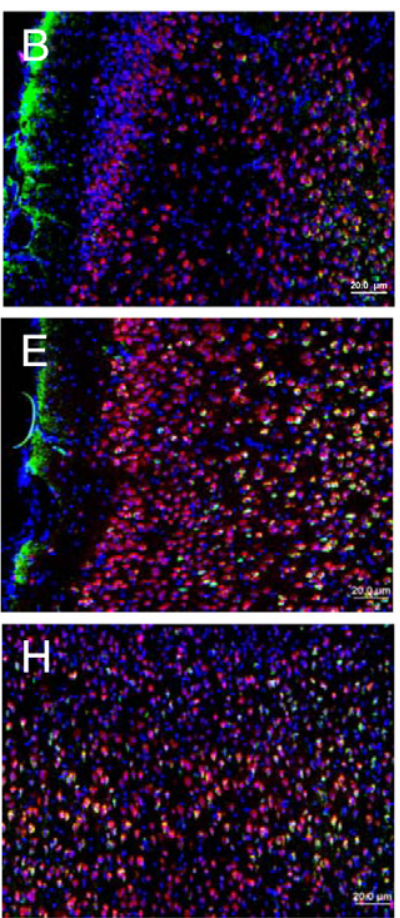

Merged
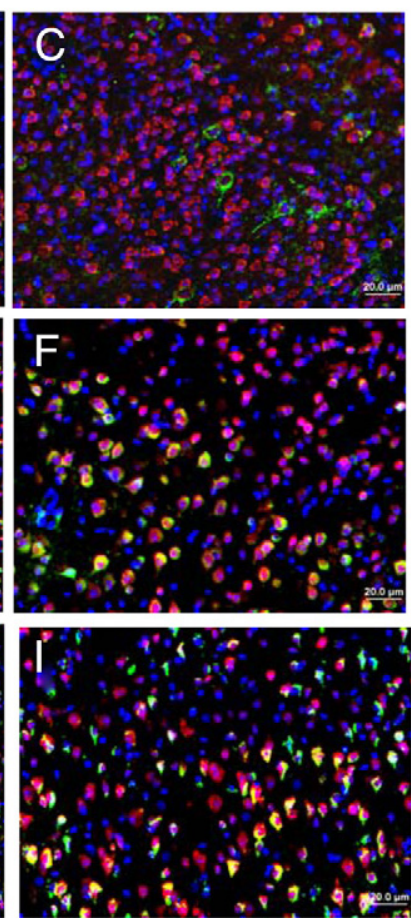

Figure 4. Effect of cerebral ischemia on neuroserpin expression in cortical neurons. Representative micrographs from the AOI-1 (left frontoparietal cortex) in wild-type mice maintained under nonischemic conditions (A-C) or 6 hours after either 30 minutes of middle cerebral artery occlusion (lethal MCAO; D-F) or three episodes of MCAO of 5-minute duration each with 10-minute intervals in between (sublethal MCAO, G-I) are shown. Original magnification, $\times 10$. The insets in $\mathbf{A}, \mathbf{D}$, and $\mathbf{G}$ represent the areas magnified in $\mathbf{C}, \mathbf{F}$, and $\mathbf{I}$. Green is neuroserpin, blue is DAPI, and red is the neuronal marker NeuN. Each observation was repeated five times. Roman numerals in $\mathbf{A}, \mathbf{D}$, and $\mathbf{G}$ indicate cortical layers.

vival to $78.2+/-1.8 \%$, and that early/immediate preconditioning with neuroserpin increases cell survival to $98.3+1-2.3 \%$ (Figure 6B).

\section{Treatment with Neuroserpin Decreases the Volume of the Ischemic Lesion in Wt and tPA ${ }^{-1-}$ Mice}

Cerebral ischemia-induced cell death is largely mediated by the deleterious effect of excitotoxins on cell survival. Thus we decided to quantify the volume of the ischemic lesion in Wt and $\mathrm{tPA}^{-1-}$ mice 24 hours after MCAO and treatment with neuroserpin injected directly into the ischemic cortex immediately after the induction of cerebral ischemia. Our results indicate that treatment with neuroserpin decreases the volume of the ischemic lesion from
$57.6+/-9.8 \mathrm{~mm}^{3}$ to $29.8+/-6.2 \mathrm{~mm}^{3}$ in Wt mice, and from $37.3+/-7.1 \mathrm{~mm}^{3}$ to $25.1+/-4.7 \mathrm{~mm}^{3}$ in tPA $^{-/-}$ mice (Figure 7A). Thus, despite a decrease in the volume of the ischemic lesion associated with genetic deficiency of tPA, treatment with neuroserpin caused a further reduction of $32.8+1-4.3 \%$ in the volume of the ischemic lesion in $\mathrm{tPA}^{-1-}$ mice (Figure $7 \mathrm{~B}$ ).

\section{Discussion}

In the brain tPA is expressed mainly in the hippocampus and cerebral cortex, ${ }^{23}$ where its presence has been associated not only with physiological processes linked to synaptic plasticity, such as learning ${ }^{4,28}$ and memory, ${ }^{29}$ but also with pathological events such as cell death ${ }^{7}$ and ischemic cerebral edema. ${ }^{2,30}$ The neurotoxic effect of tPA is
A

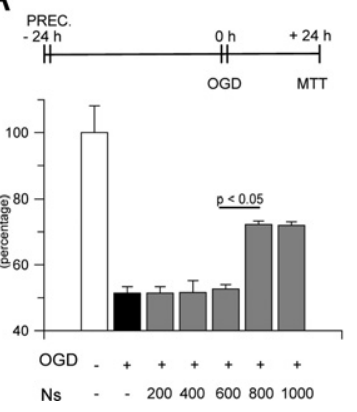

B

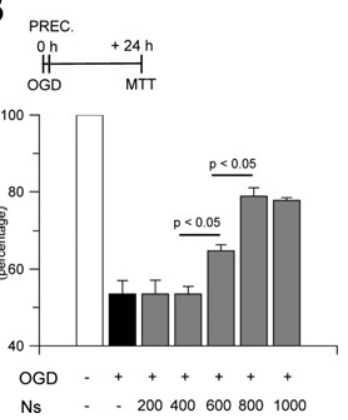

C

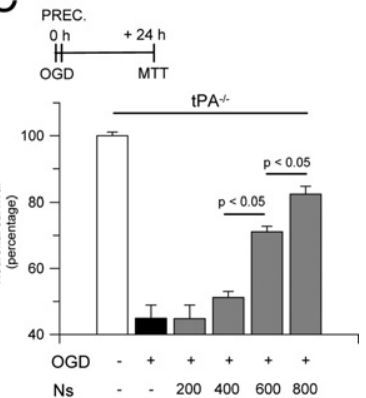

Figure 5. Neuroserpin induces hypoxic tolerance in cortical neurons via a tPA-independent mechanism. A and B: Mean neuronal survival in wild-type cortical neurons incubated with progressive concentrations of neuroserpin (Ns) followed either 24 hours later (A) or immediately after (B) by exposure to lethal OGD conditions for 55 minutes; $n=20$ for each observation. C: Mean neuronal survival in tPAdeficient $\left(\mathrm{tPA}^{-/-}\right.$) cortical neurons incubated with progressive concentrations of Ns immediately before exposure to lethal OGD conditions for 55 minutes. Lines denote SD. PREC, preconditioning. It denotes the moment when cells were treated with Ns; $n=20$ for each observation. Concentrations are given in nanomolar. 
A

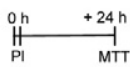

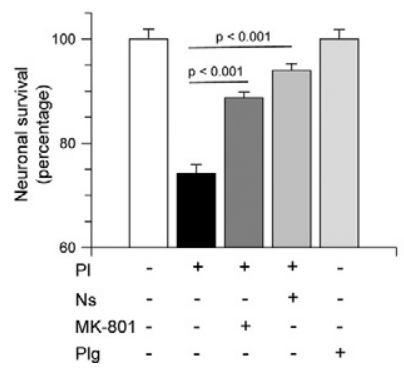

B
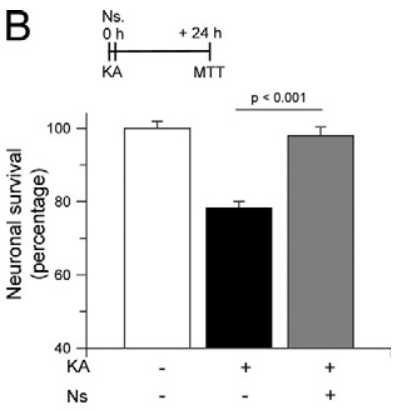

Figure 6. Preconditioning with neuroserpin inhibits excitotoxin-induced cell death. A: Mean neuronal survival in wild-type cortical neurons incubated with plasmin (Pl) $100 \mathrm{nmol} / \mathrm{L}$ alone or in combination with either MK-801 10 $\mu \mathrm{mol} / \mathrm{L}$ or neuroserpin $(800 \mathrm{nmol} / \mathrm{L})$. A subgroup of neurons was incubated with plasminogen (Plg) alone. Each observation was repeated 10 times. Lines denote SD. B: Mean cell survival in cortical neurons incubated with KA 250 $\mu \mathrm{mol} / \mathrm{L}$ either alone or in combination with Ns $800 \mathrm{nmol} / \mathrm{L}$. Each observation was repeated 15 times. Lines denote SD.

less well understood. However, recent evidence indicates that although tPA induces cortical neuronal death, it promotes cell survival in hippocampal neurons. ${ }^{16}$

Neuroserpin is a member of the serpin (serine proteinase inhibitors) gene family, primarily expressed in the brain where either tPA protein or tPA message are also found. ${ }^{10}$ Neuroserpin and tPA have been associated with the development of synaptic plasticity. Indeed, neuroserpin is widely expressed during the late phases of development, when neurons migrate and synapses are formed. Furthermore, tPA and neuroserpin expression are detected in those areas of the adult brain that retain synaptic plasticity, such as the hippocampus, cerebral cortex, and amygdala. ${ }^{23}$ Additionally, the gene for $\mathrm{tPA}^{3}$ and neuroserpin ${ }^{12}$ are up-regulated by neuronal activity, and both, tPA and neuroserpin, are released in response to neuronal depolarization, indicating that their expression is activity-regulated, a characteristic of proteins involved in synaptic plasticity.

Biochemical studies have led to the hypothesis that neuroserpin is the selective inhibitor of tPA in the CNS, ${ }^{31}$ and that neuroserpin's neuroprotective role is mediated by its ability to inhibit tPA activity. However, the observation that neuroserpin-deficient mice not only have unchanged tPA activity but also exhibit significant abnor-

A

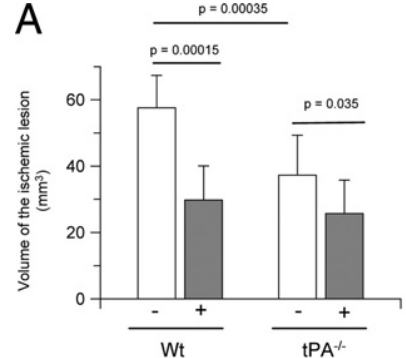

Figure 7. Effect of treatment with neuroserpin on the volume of the ischemic lesion. A: Volume of the ischemic lesion 24 hours after MCAO in Wt and tPA-deficient $\left(\mathrm{tPA}^{--}\right)$mice treated with neuroserpin $(+)$injected directly into the ischemic area; $n=12$ per experimental group. Lines denote SD. B: Percentage decrease in the volume of the ischemic lesion in Wt and $\mathrm{tPA}^{-}$ mice treated with neuroserpin immediately after MCAO; $n=12$ per experimental group. Lines denoted SD. malities in the regulation of emotional behavior, ${ }^{32}$ and that neuroserpin regulates cell adhesion independently of its activity as inhibitor of tPA activity, ${ }^{33}$ indicates the existence of tPA-independent effects for neuroserpin. In agreement with these observations, our data indicate that the neuroprotective effect of neuroserpin in the ischemic brain is at least in part independent of neuroserpin's interaction with tPA and instead mediated by inhibition of plasmin-induced cell death. Our hypothesis is supported by the fact that neuroserpin is not only a tPA- but also a plasmin-inhibitor. Importantly, our data also indicate that tPA is not the only plasminogen activator during hypoxia/ ischemia. Indeed, our previous studies revealed the presence of a significant increase not only of tPA but also urokinase-type plasminogen activator activity in the ischemic tissue following MCAO. ${ }^{8}$ Interestingly, our results also show that neuroserpin's neuroprotective effect is more prominent in $\mathrm{tPA}^{-1-}$ neurons, confirming the existence of the previously reported interaction between neuronal tPA and neuroserpin during hypoxia/ischemia. ${ }^{8}$ However, it is important to indicate that the physiological concentrations of neuroserpin in the synaptic space are largely unknown. Thus, it is impossible for us to know whether the concentrations used in our experiments reflect those found in vivo.

Excitotoxic cell death is one of the fundamental mechanisms for hypoxia/ischemia-induced neuronal demise. Our earlier studies show that plasmin relieves the inhibition of the NMDAR by zinc, ${ }^{25,26}$ and reports by others indicate that plasmin plays a role in excitotoxic-induced cell death. ${ }^{27}$ In the results presented here we show that plasmin induces neuronal death, and that this effect is abrogated by NMDAR antagonism and neuroserpin. Furthermore, our studies indicate that treatment with neuroserpin abrogates not only plasmin- but also KA-induced neuronal death. Together, these results indicate that neuroserpin's neuroprotective effect is largely mediated by its ability to inhibit plasmin-mediated excitotoxic cell death.

Cerebral ischemia is one of the most important causes of death and disability in the world. ${ }^{11}$ It has been recognized that some areas of the brain are more vulnerable to hypoxic/ischemic injury. Indeed, the CA1 hippocampal layer and cerebral cortex are among the structures of the brain with the highest susceptibility to the deleterious effects of a hypoxic/ischemic insult. Importantly, these are also the areas of the brain with the highest expression of both tPA and neuroserpin. ${ }^{10,23}$ In previous studies we showed that hippocampal hypoxia/ischemia induces a rapid increase in IPA activity in the CA1 layer associated with neuronal survival. ${ }^{16}$ The results presented here indicate that hippocampal ischemia also increases neuroserpin expression in the CA1 hippocampal layer, and that this effect is also associated with neuronal survival. These observations argue against the hypothesis that IPA inhibition is the main mechanism of neuroserpin's neuroprotective effect. It is important to note that, as already described by others, ${ }^{34}$ some granule cells also exhibit immunoreactivity for neuroserpin, suggesting a role for neuroserpin in hippocampal neurogenesis.

Ischemic preconditioning is a natural adaptive process whereby exposure to a sublethal insult induces tolerance 
against a subsequent lethal hypoxic/ischemic injury. Our previous studies indicate that IPA mediates the development of delayed but not early ischemic tolerance. ${ }^{16}$ The data presented here show that in contrast with IPA, neuroserpin induces mild delayed but strong early ischemic preconditioning. Together, these observations suggest that the protective effect of IPA and neuroserpin in the hippocampus occur at different time points via independent mechanisms.

It has been previously demonstrated that MCAO increases IPA activity and neuroserpin expression in the cerebral cortex. ${ }^{8}$ Likewise, in earlier studies we demonstrated that IPA induces a dose-dependent decrease in cortical neuronal survival. ${ }^{16}$ Furthermore, either tPA deficiency $^{13}$ or treatment with neuroserpin ${ }^{8}$ or neuroserpin gene overexpression ${ }^{14}$ is associated with decrease of the volume of the ischemic lesion following MCAO. Based on these observations, it was postulated that neuroserpin protects the ischemic cerebral cortex by inhibiting tPA and blocking tPA's deleterious effects on neuronal survival. Our data indicate that, as observed in the hippocampus, neuroserpin's neuroprotective effect in cortical neurons is independent of its ability to inhibit tPA activity. Together with our previous observations, ${ }^{2,8,30}$ our results indicate that neuroserpin has a dual beneficial role in the ischemic brain: (1) tPA-independent inhibition of excitotoxin-induced cell death, and (2) abrogation of tPA-induced increase in the permeability of the bloodbrain barrier.

\section{References}

1. Bugge TH, Kombrinck KW, Flick MJ, Daugherty CC, Danton MJ, Degen JL: Loss of fibrinogen rescues mice from the pleiotropic effects of plasminogen deficiency. Cell 1996, 87:709-719

2. Polavarapu R, Gongora MC, Yi H, Ranganthan S, Lawrence DA, Strickland D, Yepes M: Tissue-type plasminogen activator-mediated shedding of astrocytic low-density lipoprotein receptor-related protein increases the permeability of the neurovascular unit. Blood 2007, 109:3270-3278

3. Qian Z, Gilbert ME, Colicos MA, Kandel ER, Kuhl D: Tissue-plasminogen activator is induced as an immediate-early gene during seizure, kindling and long-term potentiation. Nature 1993, 361:453-457

4. Seeds NW, Williams BL, Bickford PC: Tissue plasminogen activator induction in Purkinje neurons after cerebellar motor learning. Science 1995, 270:1992-1994

5. Yepes M, Sandkvist M, Coleman TA, Moore E, Wu JY, Mitola D, Bugge $\mathrm{TH}$, Lawrence DA: Regulation of seizure spreading by neuroserpin and tissue-type plasminogen activator is plasminogen-independent. J Clin Invest 2002, 109:1571-1578

6. Mataga N, Nagai N, Hensch TK: Permissive proteolytic activity for visual cortical plasticity. Proc Natl Acad Sci USA 2002, 99:7717-7721

7. Tsirka SE, Gualandris A, Amaral DG, Strickland S: Excitotoxin-induced neuronal degeneration and seizure are mediated by tissue plasminogen activator. Nature 1995, 377:340-344

8. Yepes M, Sandkvist M, Wong MK, Coleman TA, Smith E, Cohan SL, Lawrence DA: Neuroserpin reduces cerebral infarct volume and protects neurons from ischemia-induced apoptosis. Blood 2000, 96:569-576

9. Osterwalder T, Contartese J, Stoeckli ET, Kuhn TB, Sonderegger P: Neuroserpin, an axonally secreted serine protease inhibitor. EMBO $J$ 1996, 15:2944-2953

10. Hastings GA, Coleman TA, Haudenschild CC, Stefansson S, Smith EP, Barthlow R, Cherry S, Sandkvist M, Lawrence DA: Neuroserpin, a brain-associated inhibitor of tissue plasminogen activator is localized primarily in neurons: implications for the regulation of motor learning and neuronal survival. J Biol Chem 1997, 272:33062-33067

11. Lloyd-Jones D, Adams R, Carnethon M, De SG, Ferguson TB, Flegal K, Ford E, Furie K, Go A, Greenlund K, Haase N, Hailpern S, Ho M, Howard V, Kissela B, Kittner S, Lackland D, Lisabeth L, Marelli A, McDermott M, Meigs J, Mozaffarian D, Nichol G, O'Donnell C, Roger V, Rosamond W, Sacco R, Sorlie P, Stafford R, Steinberger J, Thom T, Wasserthiel-Smoller S, Wong N, Wylie-Rosett J, Hong Y: Heart disease and stroke statistics - 2009 update: a report from the American Heart Association Statistics Committee and Stroke Statistics Subcommittee. Circulation 2009, 119:480-486

12. Berger $P$, Kozlov SV, Cinelli $P$, Kruger SR, Vogt $L$, Sonderegger $P$ : Neuronal depolarization enhances the transcription of the neuronal serine protease inhibitor neuroserpin. Mol Cell Neurosci 1999, 14:455-467

13. Wang YF, Tsirka SE, Strickland S, Stieg PE, Soriano SG, Lipton SA: Tissue plasminogen activator (tPA) increases neuronal damage after focal cerebral ischemia in wild-type and tPA-deficient mice. Nat Med 1998, 4:228-231

14. Cinelli P, Madani R, Tsuzuki N, Vallet P, Arras M, Zhao CN, Osterwalder T, Rulicke T, Sonderegger P: Neuroserpin, a neuroprotective factor in focal ischemic stroke. Mol Cell Neurosci 2001, 18:443-457

15. Kitagawa K, Matsumoto M, Kuwabara K, Tagaya M, Ohtsuki T, Hata R, Ueda H, Handa N, Kimura K, Kamada T: "Ischemic tolerance" phenomenon detected in various brain regions. Brain Res 1991, 561:203-211

16. Echeverry R, Wu J, Haile WB, Guzman J, Yepes M: Tissue-type plasminogen activator is a neuroprotectant in the mouse hippocampus. J Clin Invest 2010, 120:2194-2205

17. Zhang X, Polavarapu R, She H, Mao Z, Yepes M: Tissue-type plasminogen activator and the low-density lipoprotein receptor-related protein mediate cerebral ischemia-induced nuclear factor-kappaB pathway activation. Am J Pathol 2007, 171:1281-1290

18. Belayev L, Busto R, Zhao W, Fernandez G, Ginsberg MD: Middle cerebral artery occlusion in the mouse by intraluminal suture coated with poly-L-lysine: neurological and histological validation. Brain Res 1999, 833:181-190

19. Stagliano NE, Perez-Pinzon MA, Moskowitz MA, Huang PL: Focal ischemic preconditioning induces rapid tolerance to middle cerebral artery occlusion in mice. J Cereb Blood Flow Metab 1999, 19:757-761

20. Paxinos G, Franklin KBJ: The Mouse Brain in Stereotaxic Coordinates. San Diego, Academic Press Inc., 2001, pp 1-93

21. Zhang X, Winkles JA, Gongora MC, Polavarapu R, Michaelson JS Hahm K, Burkly L, Friedman M, Li XJ, Yepes M: TWEAK-Fn14 pathway inhibition protects the integrity of the neurovascular unit during cerebral ischemia. J Cereb Blood Flow Metab 2007, 27:534-544

22. Greene JG, Borges K, Dingledine R: Quantitative transcriptional neuroanatomy of the rat hippocampus: evidence for wide-ranging, pathway-specific heterogeneity among three principal cell layers. Hippocampus 2009, 19:253-264

23. Teesalu T, Kulla A, Simisker A, Siren V, Lawrence DA, Asser T, Vaheri $A:$ Tissue plasminogen activator and neuroserpin are widely expressed in the human central nervous system. Thromb Haemost 2004, 92:358-368

24. Osterwalder T, Cinelli P, Baici A, Pennella A, Krueger SR, Schrimpf $\mathrm{SP}$, Meins $\mathrm{M}$, Sonderegger $\mathrm{P}$ : The axonally secreted serine proteinase inhibitor, neuroserpin, inhibits plasminogen activators, and plasmin but not thrombin. J Biol Chem 1998, 273:2312-2321

25. Mannaioni G, Orr AG, Hamill CE, Yuan H, Pedone KH, McCoy KL, Palmini RB, Junge CE, Lee CJ, Yepes M, Hepler JR, Traynelis SF: Plasmin potentiates synaptic $\mathrm{N}$-methyl-D-aspartate receptor function in hippocampal neurons through activation of protease-activated receptor-1. J Biol Chem 2008, 283:20600-20611

26. Yuan H, Vance KM, Junge CE, Geballe MT, Snyder JP, Hepler JR, Yepes M, Low CM, Traynelis SF: The serine protease plasmin cleaves the amino-terminal domain of the NR2A subunit to relieve zinc inhibition of the N-methyl-D-aspartate receptors. J Biol Chem 2009, 284:12862-12873

27. Tsirka SE, Bugge TH, Degen JL, Strickland S: Neuronal death in the central nervous system demonstrates a non-fibrin substrate for plasmin. Proc Natl Acad Sci USA 1997, 94:9779-9781

28. Seeds NW, Basham ME, Ferguson JE: Absence of tissue plasminogen activator gene or activity impairs mouse cerebellar motor learning. J Neurosci 2003, 23:7368-7375 
29. Baranes D, Lederfein D, Huang YY, Chen M, Bailey CH, Kandel ER: Tissue plasminogen activator contributes to the late phase of LTP and to synaptic growth in the hippocampal mossy fiber pathway. Neuron $1998,21: 813-825$

30. Yepes M, Sandkvist M, Moore EG, Bugge TH, Strickland DK, Lawrence DA: Tissue-type plasminogen activator induces opening of the blood-brain barrier via the LDL receptor-related protein. J Clin Invest 2003, 112:1533-1540

31. Yepes M, Lawrence DA: Neuroserpin: a selective inhibitor of tissuetype plasminogen activator in the central nervous system. Thromb Haemost 2004, 91:457-464
32. Madani R, Kozlov S, Akhmedov A, Cinelli P, Kinter J, Lipp HP, Sonderegger P, Wolfer DP: Impaired explorative behavior and neophobia in genetically modified mice lacking or overexpressing the extracellular serine protease inhibitor neuroserpin. Mol Cell Neurosci 2003, 23:473-494

33. Lee TW, Coates LC, Birch NP: Neuroserpin regulates N-cadherinmediated cell adhesion independently of its activity as an inhibitor of tissue plasminogen activator. J Neurosci Res 2008, 86:1243-1253

34. Yamada M, Takahashi K, Ukai W, Hashimoto E, Saito T, Yamada M Neuroserpin is expressed in early stage of neurogenesis in adult rat hippocampus. Neuroreport 2010, 21:138-142 